\title{
Histochemical localization of cytokinin oxidase/dehydrogenase during the developmental stages of Withania somnifera (L.) Dunal
}

\begin{abstract}
Ananthapadmanaban Saravanakumar, Abubakker Aslam and Appakan Shajahan*
PG and Research Department of Botany, Jamal Mohamed College, Tiruchirappalli - 620 020, Tamilnadu, India.

Accepted 25 March, 2011

Withania somnifera (L.) Dunal is a promising herb that has been used as both traditional and modern therapeutic agent by virtue of its bioactive compounds especially withanolides. Earlier in vitro studies revealed the relation between cytokinin (CK) level and biogeneration of withanolides. The information on the cytokinin metabolism in $W$. somnifera is lacking. The role of enzymes involved in cytokinin metabolism can provide the link between the level of cytokinin and withanolide production. CK is a plant growth regulator playing crucial role in almost all the developmental processes. It is agreed that, the oxidative breakdown of CK by cytokinin oxidase $(C K X)$ is an important process by which plant tissues control the levels and distribution of CK. This paper reports histochemical localization of $C K X$ at various developmental stages of $W$. somnifera.
\end{abstract}

Key words: Cytokinin oxidase/dehydrogenase, Withania somnifera, CKX localization.

\section{INTRODUCTION}

Cytokinin (Ck) is a plant hormone that plays a crucial role in many fundamental processes of plant development throughout the life cycle. These include seed germination, cotyledon expansion, chloroplast differentiation, de-etiolation, differentiation of vascular tissue, apical dominance (shoot branching), root elongation and branching, nutritional signaling, regulation of sink strength, the transition from the vegetative to the reproductive growth phase, flower and fruit development, leaf senescence and plant-pathogen interactions (Mok and Mok, 2001; Oka, 2003; Schmülling, 2004). Cytokinin levels in every individual plant cells, tissues and organs are crucial in all the earlier mentioned process, it depends on cytokinin biosynthesis and/or uptakes from extracellular sources, metabolic inter conversions, inactivation and degradation. Although, the formation of cytokinin conjugates is involved in controlling the abundance of active cytokinins, it is agreed that, the oxidative breakdown of cytokinins is an important process

${ }^{\star}$ Corresponding author. E-mail: shajahan.jmc@gmail.com. Tel: +91-9842975656. Fax: +91-431-2331035. by which plant tissues might control the levels and distribution of cytokinins. Cytokinins are selectively inactivated by the oxidative cleavage of their side chains and the only plant enzyme which catalyses this degradation is known as cytokinin oxidase/ dehydrogenase (CKX; EC 1.5.99.12). Therefore, this enzyme holds high importance among researchers to understand and reveal the role of cytokinin in the developmental process.

Ashwagandha (Withania somnifera L. Dunal., SOLANACEAE) is one of the most reputed Indian medicinal plants. Pharmacological activities of this plant includes physiologic and metabolic restoration, antiarthritic, anti-ageing, nerve tonic, cognitive function improvement in geriatric states and recovery from neurodegenerative disorders like convulsions, tardive dyskinesia, etc, (Dhuley, 2000; Bhattacharya et al., 2002) Recent investigations have elucidated the association of these activities with specific secondary metabolites known as withanolides. These withanolides are present in very low levels in the natural plant and abundantly in the roots. The in vitro studies have revealed that, the cytokinin combinations (benzyl adenine and kinetin) are not only influenced by their morphogenetic response but 
also differentially modulating the level (10 fold increase) of biogeneration of withanolide $A$ in the in vitro shoots of W. somnifera (Sangwan et al., 2007). This report allows us to think that cytokinin also plays a role in the secondary metabolite production. In contrast to the positive role of CKs on shoot apical meristem (SAM), an opposite effect of CK on root growth had been observed in transgenic Arabidopsis and tobacco that have reduced CK level by the constitutive expression of CKX genes (Werner et al., 2001). Understanding the cytokinin metabolism of medicinally and economically valuable plants like $W$. somnifera will help us to improve the economically important developmental aspects of the plant such as increasing the secondary metabolite (Withanolide A) production and the root biomass. Comparisons of $C K X$ activity among plant tissues are commonly made on the basis of relative activity in tissue homogenates but there are varieties of cytoplasmic and cell wall-associated constituents that can serve as electron acceptors for $C K X$ with variable efficiency (Galuszka et al., 2001; Frébortová et al., 2004). The in vitro assay developed by Galuszka et al. (2005) using 2,6-Dichlorophenol indophenol (DCPIP) is capable of providing quantitative measure of enzyme activity irrespective of the $C K X$ family. But, the location specific activity of $C K X$ can be confirmed visually only by in situ assays. In the present study, the purple precipitate formation as the result of electron transfer through a redox indicator dye combination was used to reflect dehydrogenase activity of the CKX (Šebela et al., 2001). To gain better understating of spatial and temporal variation of $C K X$ activity in various developmental stages, histo-chemical localization of $C K X$ activity has been carried out in W. somnifera.

\section{MATERIALS AND METHODS}

\section{Plant material}

Fresh seeds of $W$. somnifera were collected from the field grown plant. Seeds were soaked in distilled water for one day and germinated in the pot containing garden soil kept in the net house. Leaf, stem and roots were sampled after thirty days of growth. Flower buds were collected at different stages from three months old plants. Free hand sections were made from these samples and immersed in $0.2 \mathrm{M}$ Tris $-\mathrm{HCl}, \mathrm{pH} 8.0$ in order to maintain the osmoticum. From these materials, thin sections were collected and taken for the $C K X$ activity localization studies.

\section{Histochemical localization of $C K X$}

Sections were immediately stained for $C K X$ activity in the staining solution containing $5 \mathrm{mM}$ isopentenyladenine (substrate), $0.15 \mathrm{mM}$ phenazine methosulfate and $0.75 \mathrm{mM}$ nitroblue tetrazolium in $0.2 \mathrm{M}$ Tris- $\mathrm{HCl}$ buffer, $\mathrm{pH}$ 8.0. For all the samples, control is kept in the staining solution without the substrate. Tissues were incubated in the dark for $24 \mathrm{~h}$ at $37^{\circ} \mathrm{C}$ and for every six hours, sections were transferred to the fresh staining solution. Finally, sections were examined under Olympus ${ }^{\mathrm{TM}}$ light microscope for blue colored product formation.

\section{RESULTS AND DISCUSSION}

The fixed whole seedling showed discontinuous colour formation indicating that the activity of $C K X$ is tissue specific. The stem above the crown region did not show any colour formation, whereas the whole root system below the crown showed intense CKX activity (Figure 1a). Table 1 shows the various qualitative expression proved by the histochemical staining in various locations of a cells and tissues. The experiment was controlled by staining fixed plant tissues without substrate (Galuszka, 2005) that did not provide any staining of the CKX activity (Figure 1b).

The epidermis, the outermost cell layer, is a complex tissue that covers the entire plant surface consisting of many specialized cell types such as root hairs, stomata, trichomes, secretory and tissues that develop into floral tissue. In W. somnifera staining pattern, in situ CKX activity reveals that the enzyme activity was not detected in the epidermal layers of leaf, stem and root. But interestingly, the epidermal outgrowth and the leaf trichome showed prominent $C K X$ activity (Figure 1c, d, f). Floral bud and the floral whorls invariably showed the prominent activity of $C K X$ (Figure 1i). In W. somnifera, all other parts except the leaf have branched non glandular trichome, but the leaves have both branched glandular and non glandular trichome. This branched glandular trichome has multicellular stalk with secretory head. The $C K X$ activity is restricted to stalk region only, not in the secretory head (Figure 1g). Another epidermal outgrowth in root region (that is, root hairs) also has higher $C K X$ activity (Figure 1c). The stomata present are in all stages of leaf and the CKX activity was restricted significantly to the cell wall of the guard cells that were lining the stomata cavity (Figure 1h). All these domains observed for higher $C K X$ activity (trichomes and stomata lining) are reported to be the expression domains of IPT genes in Arabidopsis (Miyawaki et al., 2004). This observation supports the view of Werner et al. (2006) that, cytokinins are degraded in the same tissue where they are synthesized in cases of cell division or endoreduplication.

Three to four layers of cells in the outer cortex region of the stem and root have shown relatively higher activity of $C K X$. These cell layers with high $C K X$ activity might regulate the movement of cytokinins in the outer environment from perturbing the growth or cell division. In flower, the parts of non-essential floral whorls such as calyx and corolla have not shown any sign of $C K X$ activity whereas in the bud stage, the vascular tissue and medullary region of sepals and petals showed slight activity of $C K X$ (Figure 1i, j, k). Except the bud, all stages of flower have shown higher CKX activity at the basal region (Figure $11, m$ ) from where conduction of food and growth regulators transportation to the developing parts takes place. The stamen typically shows slight CKX 

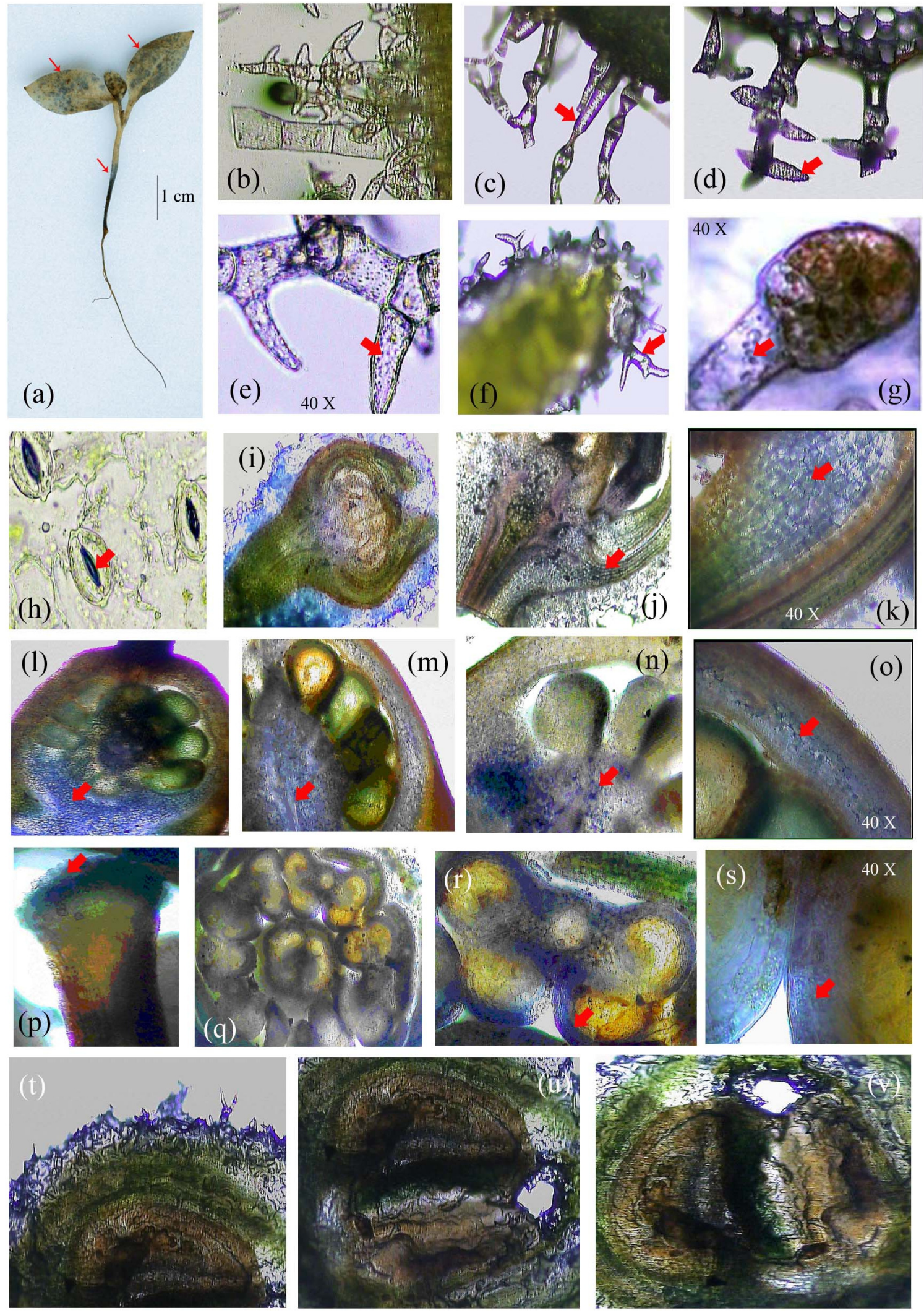

Figure 1. Light microscopic localization of cytokinin oxidase $(C K X)$ gene in $W$. somnifera. (a) Whole seedling showing histochemical localization of CKX activity; (b) to(g) trichomes showing CKX activity; (h)Lower epidermis of leaf showing stomatal cavity with CKX activity; (i) to (s) Various floral parts showing CKX activity; (t) to (v) seeds not showing any $C K X$ activity. All the images are of the $20 \times$ magnification unless stated. 
Table 1. Comparison of relative $C K X$ activity in various organs and tissues of $W$. somnifera.

\begin{tabular}{|c|c|c|c|c|}
\hline $\mathbf{S} / \mathbf{N}$ & Tissue & $\begin{array}{c}\text { Relative } C K X \\
\text { activity }\end{array}$ & $\begin{array}{c}\text { Cytosol/cell } \\
\text { wall }\end{array}$ & Remark \\
\hline 1 & Epidermal glandular trichome & +++ & Cytosol & Stalk cell only \\
\hline 2 & Secretary glandular trichome & - & - & Absence of activity. \\
\hline 3 & Root hairs & +++ & Cytosol & High degree of $C K X$ activity \\
\hline 4 & Stomatal outline of guard cells wall & +++ & Cell wall & $\begin{array}{l}\text { Activity is seen only in cell walls surface in } \\
\text { stoma }\end{array}$ \\
\hline 5 & Flower bud calyx & - & - & $C K X$ activity undetectable \\
\hline \multirow[t]{2}{*}{6} & Flower bud corolla & - & - & $C K X$ activity undetectable \\
\hline & Basal region of flower bud & - & - & $C K X$ activity undetectable \\
\hline 7 & Medullary region of mature calyx & ++ & Cell wall & Cell wall is found to have $C K X$ activity \\
\hline 8 & Medullary region of mature corolla & ++ & Cytosol & $\begin{array}{l}\text { Medullary region is found to have less } C K X \\
\text { activity }\end{array}$ \\
\hline 9 & Basal region of mature flower & +++ & Cytosol & $\begin{array}{l}\text { Basal region of mature flower is found to } \\
\text { have more } C K X \text { activity }\end{array}$ \\
\hline 10 & Stamen - filament & + & Cytosol & - \\
\hline 11 & $\begin{array}{l}\text { Anther wall - epidermis, endothecium } \\
\text { and tapetum. }\end{array}$ & +++ & Cytosol & $\begin{array}{l}\text { Anther wall layers are found to have more } \\
\text { CKX activity. }\end{array}$ \\
\hline 12 & Seed endosperm & - & - & $C K X$ activity undetectable \\
\hline
\end{tabular}

activity only at maturity in the filament region and in the anther walls (epidermis, endothecium and tapetum) (Figure 1q, r, s). Among the carpellary tissues, papillae of stigma, the placental, chalazal tissue and the medullary region of carpellary wall of the ovary have shown the activity of $C K X$ (Figure $11, \mathrm{~m}, \mathrm{n}, \mathrm{o})$. Similar observation was made in maize where cytokinin content and CKX activity were higher in the tissues of pedicel, placenta and chalaza and lower in the endosperm (Jones et al., 1992; Brugiere et al., 2003). This observation supports the hypothesis that, $C K X$ protein(s) may control the growth and development of seed tissues by regulating the cytokinin import from vegetative tissues (Jones and Schreiber, 1997; Brugiere et al., 2003).

Cytokinin biosynthesis is catalyzed by IPT (isopentenyItransferase) enzymes encoded by small multi-gene family with at least seven (Arabidopsis) to eight (Oryza) members (Kakimoto, 2001; Takei et al., 2001; Sakamoto et al., 2006). Different sub-cellular isoforms of IPT enzymes were already localized proving that, the biosynthesis can occur in the cytosol, chloroplast and mitochondria (Werner et al., 2006). Similar to IPT enzyme, the $C K X$ is also encoded by multi-gene family. The fully annotated Arabidopsis genome contains seven $C K X$ genes (AtCKX1 - AtCKX7) and analysis of the entire rice genome contains at least eleven $C K X$ homologues (OsCKX1 - OsCKX11) (Werner et al., 2006). The $C K X$ multi-gene in their genome must be needed to control the level of cytokinin synthesized by IPT in various sub-cellular locations.

All these observation made in various organs of $W$. somnifera has given some strong ideas such as, CKX playing a vital role in various aspects of plant development. Their expression should be controlled by complicated regulating mechanism evidenced by the diversity of histological locations. The activity seen in many tissues is supporting that $C K X$ could act as a "gate keeper" responsible for cytokinin degradation around the sites of cytokinin biosynthesis where modulation of cytokinin level is required. Molecular characterization of $C K X$ isoforms with tools such as cDNA synthesis can provide more information on the molecular biology of 
cytokinin metabolism. The findings in this paper open a new avenue for studying the possibility of engineering cytokinin related metabolic reactions in this promising medicinal herb (Sangwan et al., 2007).

\section{ACKNOWLEDGEMENTS}

The authors acknowledge the University Grants Commission, New Delhi for financial support (F.No.33-174/2007 SR) and Department of Science and Technology, New Delhi for supporting the P.G and Research Department of Botany through DST-FIST Program.

\section{REFERENCES}

Bhattacharya SK, Bhattacharya D, Sairam K, Ghosal S (2002). Effect of Withania somnifera glycowithanolides on a rat model of tardive dyskinesia. Phytomedicine, 9: 167-170.

Brugière N, Jiao S, Hantke S, Zinselmeier C, Roessler JA, Niu X, Jones RJ, Habben JE (2003). Cytokinin oxidase gene expression in maize is localized to the vasculature, and is induced by cytokinins, abscisic acid, and abiotic stress. Plant Physiol. 132: 1228-1240.

Dhuley J (2000). Adaptogenic and cardioprotective action of ashwaganda in rats and frogs. J. Ethnopharmacol., 70: 57-63.

Frébortová J, Fraaije MW, Galuszka P, Šebela M, Pec P, Hrbác J, Novák O, Bilyeu KD, English JT, Frébort I (2004). Catalytic reaction of cytokinin dehydrogenase: preference for quinones as electron acceptors. Biochemical J., 380: 121-130.

Galuszka P, Frébort I, Šebela M, Sauer P, Jacobsen S, Pec P (2001). Cytokinin oxidase or dehydrogenase? Mechanism of cytokinin degradation in cereals. Eur. J. Biochem., 268: 450.-61.

Galuszka P, Frébortová J, Luhová L, Bilyeu KD, English JT, Frébort I (2005). Tissue localization of cytokinin dehydrogenase in maize: possible involvement of quinone species generated from plant phenolics by other enzymatic systems in the catalytic reaction. Plant and Cell Physiol. 46: 716-728.
Jones RJ, Schreiber BMN (1997). Role and function of cytokinin oxidase in plants. Plant Growth Regul. 23: 123-134.

Jones RJ, Schreiber BMN, McNeil K, Brenner M, Foxon G (1992) Cytokinin levels and oxidase activity during maize kernel development. In Physiology and Biochemistry of Cytokinins in Plants (Kaminek M, Mok DWS, and Zazimalova E, eds.), The Hague: SPB Academic Publishing, pp. 235-239.

Miyawaki K, Matsumoto-Kitano M, Kakimoto T (2004). Expression of cytokinin biosynthetic isopentenyltransferase genes in Arabidopsis: tissue specificity and regulation by auxin, cytokinin, and nitrate. Plant J. $37: 128-138$

Mok DW, Mok MC (2001). Cytokinin metabolism and action. Ann. Rev. Plant Physiol. Plant Mol. Biol., 52: 89-118.

Oka A (2003). New insights into cytokinins. J. Plant Res., 116: 217220.

Sakamoto T, sakakibara H, Kojima M, Yamamota Y, Nagasaki H, Inukai Y, Sato Y, Matsuoka M (2006). Ectopic expression of KNOTTED1 like homeodomain protein induces expression of cytokinin biosynthesis genes in rice. Plant Physiol. 9: 1-16.

Sangwan RS, Chaurasiya ND, Lal P, Misra L, Uniyal GC, Tuli R, Sangwan NS (2007). Withanolide A biogeneration in in vitro shoot cultures of Aswagandha (Withania somnifera Dunal.), a main medicinal herb in Ayurveda. Chem. Pharm. Bull. 55(9): 1371-1375.

Šebela M, Luhová L, Brauner F, Galuszka P, Radová A, Pec P (2001). Light microscopic localisation of aminoaldehyde dehydrogenase activity in plant tissues using nitroblue tetrazolium-based staining method. Plant Physiol. Biochem., 39: 831-839.

Takei K, Sakakibara H, Sugiyama T (2001). Identification of genes encoding adenylate isopentenyltransferase, a cytokinin biosynthesis enzyme, in Arabidopsis thaliana. J. Biol. Chem., 276: 26405-26410.

Werner T, Köllmer I, Bartrina I, Holst K, Schmülling T (2006). New Insights into the biology of cytokinin degradation. Plant Biol. 8: 371 381

Werner T, Motyka V, Strnad M, Schmülling T (2001). Regulation of plant growth by cytokinin. Proc. Nat. Acad. Sci., USA. 98: 10487-10492. 